\title{
The Philippine Policy Context for eHealth
}

\author{
James A. Salisi, ${ }^{1}$ Jay Pee Z. Cruz, ${ }^{1}$ Sophia Francesca DP. Lu² and Portia H. Fernandez-Marcelo ${ }^{1}$ \\ ${ }^{1}$ National Telehealth Center, National Institutes of Health, University of the Philippines Manila \\ ${ }^{2}$ Department of Social Sciences, University of the Philippines Manila
}

\begin{abstract}
Background: eHealth in the Philippines is poised to take off but adoption of eHealth applications in the country's public health sector is limited in scale.

Objective: This paper examines the context and status of eHealth policy in the Philippines. The aim is to lay out the domains of policy issues that should be addressed for the successful implementation of eHealth in the Philippines.
\end{abstract}

Methods: The themes and issues of policies on eHealth cited by Khoja, Durrani, Nayani and Fahim (2012) were used to describe and analyze the status of eHealth policy context in the Philippines. These are: (1) networked care, (2) interjurisdictional practice, (3) diffusion of eHealth/digital divide, (4) eHealth integration with existing systems, (5) response to new initiatives, (6) goal-setting for eHealth policy, (7) evaluation and research, (8) investment, and (9) ethics in eHealth. Documents and policies in the form of enacted laws, memoranda, implementing rules and regulations were retrieved and reviewed to answer whether or not policy themes and issues are addressed currently.

Results and Conclusion: Current policies in the status quo do not adequately address the issues that enable effective implementation of eHealth in the Philippines. While preconditions for eHealth to flourish such as strategic frameworks for ICT and eHealth have been established, they are inadequate in addressing licensing, diffusion of innovation, handling innovation, evaluation and research, and investment.

Key Words: eHealth Policy, Telehealth, Philippine eHealth, Khoja's policy domains

\section{Introduction}

Electronic health, or ehealth, is defined as "a set of statements, directives, regulations, laws, and judicial interpretations that direct and manage the life cycle of eHealth".

Presented at the National Telehealth Symposium, July 3, 2013, The Bayleaf Hotel, Intramuros, Manila.

Corresponding author: James A. Salisi, MD

National Telehealth Center

National Institutes of Health

University of the Philippines Manila

3rd Floor IT Complex, Philippine General Hospital

Taft Ave., Ermita, Manila 1000 Philippines

Telephone: +6325091003

Email: james.a.salisi@gmail.com
Telehealth is also coined with the definition of eHealth and is defined as the use of communication, diagnostic and information technology when patients and health care providers are limited by certain barriers such as geography, professional availability, limitation of transportation, infrastructure, and even socioeconomic disparity. ${ }^{2-5}$ It is in fact a tool in delivering healthcare to the underprivileged and underserviced areas in society. Additionally, telehealth is also defined as the new approach to healthcare delivery through the use of advanced telecommunications technologies to exchange health information and provide health care services across geography, time, social, and cultural barriers, as well as a vital health care tool in preventing health disparities created by geography, age, homebound status, economic position and political vulnerability. ${ }^{6}$ Telehealth is also seen as a venue for improving healthcare access in vulnerable populations through the use of electronic devices. ${ }^{7,8}$

Published in 2012, the paper by Khoja et al. on the scope of policy issues in eHealth was first presented in the 2008 at the Bellagio Conference on eHealth. ${ }^{9}$ A report commissioned for the event, Khoja et al. analyzed peer-reviewed and grey literature for policy issues, which are aspects of eHealth implementation that need to be addressed. In the course of their review, they identified 99 policy issues related to eHealth which they categorized into nine policy domains. These 9 policy domains and their definitions and various elements were adopted in this study.

The Philippines has no existing law with which the institutionalization of telehealth can be facilitated at the national level, although there are several related laws, rules, regulations, and directives on eHealth and telehealth. Currently, a House Bill has been filed in the $15^{\text {th }}$ Congress by Hon. Joseph Abaya with regard to the subject matter. The said bill, entitled "An Act Promulgating a Comprehensive Policy for a National System for TeleHealth Service in the Philippines" (House Bill 6336 of the 15 Republic of the Philippines), is still under review on the Congress floor. It has been three years since the filing of the bill, however, no immediate action has been done to facilitate its passage into law. Contained in the bill are the essential components of eHealth such as regulation, infrastructure, leadership, interoperability of the system, ethics of eHealth, applicability and access by underserved communities. The bill indicates that the lead agency for 
providing the structures and institutions for the foundation eHealth in the country is the Department of Health (DOH).

There are vital and overarching principles of eHealth which can make health accessible and affordable to the public, and one of which is that it is a great equalizer.

\section{Overarching Principle: eHealth as a Great Equalizer}

eHealth is a great equalizer with the ability to "dramatically improve health systems from Johannesburg to Jakarta" and address health inequalities, and this was reiterated by the Most Reverend Desmond Tutu, Archbishop emeritus of Cape Town, South Africa in 2009.10 Around the world, experts have recognized the potential of this emerging discipline to improve health outcomes. eHealth through the use of information and communication technologies (ICT) for health has also been used "to mediate health, healthcare, health education, or health research". ${ }^{11}$ Evidence from low- and middle-income countries shows that eHealth has been used to increase access to health care in remote areas, improve data management, diagnosis and treatment, and improve transactions in health services. ${ }^{12}$ Likewise, the Bellagio eHealth Call to Action in 2008 urged actors in various sectors to work on a set of actions for the attainment around the globe of eHealth benefits. It is a commitment to work on policy- and evidence-based agenda setting, fostering collaborative networks and global partnerships, knowledge and capacity building, globally reusable metrics, tools and templates, and supporting country-level initiatives. ${ }^{13}$ Thus, eHealth can cut across socio-economic barriers and experts recognized the need to concentrate efforts on areas that will enable developing countries to maximize the benefits of eHealth.

Although many of the eHealth applications originated in the developed world, recent innovations in the use of ICT for health are increasingly coming from developing countries in Africa and Asia. In the Philippines, for instance, eHealth applications in health services delivery, disease surveillance and information management are being developed. In Africa, mobile health applications address a spectrum of services for HIV and other infectious diseases in addition to providing logistical support. ${ }^{14}$

\section{Objectives and Scope of the Study}

This paper examines the context and status of eHealth policy in the Philippines. The aim is to lay out the domains of policy issues that should be addressed for the successful implementation of eHealth in the Philippines. In order to meet this objective, detailed review of the literature was used to determine the scope of policy issues faced by individuals, institutions, and governments in implementing eHealth programs. The study does not recommend any policies or suggest the importance of any of the policy issues over the others.
Furthermore, the focus is on public eHealth, and does not include yet the private eHealth although both are important in the success of eHealth. eHealth within the domain of the government and public institutions is targeted in this research paper since the government, both national and local, plays a central role in solving the discrimination and marginalization of certain populations in society due to lack of access to information and services affecting both personal and community health.

This paper does not intend to recommend any policies, but merely to suggest points for consideration in the eventual policy analysis of eHealth that can be used or referenced by other researchers and evaluators. This study does not also intend to weigh the various policy issue domains, or attempt to identify which should be prioritized. It is merely descriptive in nature in the hope that baseline yet comprehensive domains for policy analysis of eHealth can eventually be effected or pursued. This paper will also present implementation issues rather than outcome issues.

\section{Methods}

In the policy evaluation study of Khoja et al., they identified the key factors for the proper implementation of eHealth at the international and national levels by specifically looking at the various stakeholders such as the individuals, institutions, and governments which are key players in the success of eHealth. ${ }^{9}$ This is within the premise that eHealth is an important tool in improving health care delivery and information particularly targeting underserved populations. This approach was used by this study on eHealth analysis in the Philippines because of the comprehensive methodology of Khoja's approach which was the basis of coming up with a framework for eHealth implementation.

Using Scope of Policy Issues in eHealth by Khoja et al., an Internet search and review of relevant laws, regulations, plans from National Agency (DOH, DOTC, Congress, etc.) websites and databases were done. A combination of terms Philippine eHealth policy, telemedicine, telehealth, laws, eHealth, and regulations - were used for each policy issue identified in the paper by Khoja.

A rigorous method of data extraction and analysis was done. First, all and related laws, if any, regulations and guidelines, promulgated by the government through Congress or relevant national agency that address or at the very least tried to address it were searched starting in July 2012. An initial list of policies was created in August 2012 and to this list, other policies were added as they became available. Recent changes in laws and developments in eHealth policy in the Philippines up to May 2013 are reflected here. Then these were matched up with the policy domains laid out by Khoja et al consisting of nine domains which are: (1) networked care, (2) interjurisdictional practice, (3) diffusion of eHealth/digital divide, (4) eHealth 
integration with existing systems, (5) response to new initiatives, (6) goal-setting for eHealth policy, (7) evaluation and research, (8) investment, and (9) ethics in eHealth. The levels were determined based on where they needed to be developed: (a) global, (b) jurisdictional (national and provincial/subnational), and (c) individual institutions or practice. The first level of analysis was done by medical fellows and research assistants who were trained on the variables laid out by Khoja et al. Then a second-level of analysis was done by the telehealth consultants who have training and formal education on the subject matter. These two levels of analysis ensured that corresponding items and variables that were itemized and compared were accurate and valid.

\section{Results}

The various laws, policies and programs on and related to eHealth in the Philippines in this study are summarized in Table 1. These various laws, policies and programs were categorized as falling under any of the nine policy domains laid out by Khoja et al.

In Khoja's policy domain, the first is networked care. There are 24 issues under networked care (Table 2). Out of the 24 issues, only 10 have been addressed in the Philippine setting. Gaps exist in creating an enabling environment and sharing of information, knowledge and practice. The enactment of the Data Privacy Act of 2011 addresses the issue of making the transfer of information safer because it protects the privacy of Filipinos and regulates the transfer of personal information in all sectors of the Philippines. It also offers protection regarding information gathered in the country and stored abroad.

The second domain is interjurisdictional practise. The Philippines as part of the international community, through the economic integration promoted by the ASEAN, is confronted with easing of restrictions in cross-border practice of professions such as medicine, accounting, and law. This opens up the practice of medicine in the Philippines to foreign counterparts. A policy on this matter is needed to ensure that healthcare between different jurisdictions is well-defined and coordinated. Only one out of four issues is addressed by present policies (Table 3).

The third policy domain is connectivity. This is essential for the diffusion of eHealth. This theme deals with increasing access to health information through ICT and thereby maximizing the reach and benefits of eHealth. Three out of the 7 issues are addressed by Philippine policies (Table 4). While there is high mobile phone penetration rate, at the same time there is a wide digital divide in the Philippines. Only $47 \%$ of cities and municipalities have broadband access and $20 \%$ of households have computers. The Internet penetration rate in the Philippines has steadily increased over the years with 35\% in 2012 from 9\% in 2009 but it has largely been confined to urban areas. ${ }^{15}$ Access in rural areas is poor or non-existent. In contrast, mobile phone penetration rate is high at $92 \%$ in 2011 , with over 87 million mobile phone subscribers for a total population of 94.5 million Filipinos. ${ }^{16}$

Table 1. Summary of eHealth policy domains and relevant policies and programs in the Philippines

\begin{tabular}{|c|c|}
\hline Policy Domain & Relevant Policies/Programs \\
\hline \multirow[t]{3}{*}{ Networked Care } & DOH Information Systems Strategic Plan (ISSP) 2011-2013 \\
\hline & RA 10173: Data Privacy Act of 2012 \\
\hline & RA 9995:Anti-Photo and Video Voyeurism Act of 2009 \\
\hline \multirow[t]{6}{*}{ Interjurisdictional Practice } & RA 2382: The Medical Act of 1959 \\
\hline & RA 7392: Philippine Midwifery Act of 1992 \\
\hline & $\begin{array}{l}\text { RA 5181: Act prescribing permanent residence and reciprocity as qualifications for any examination or registration for the } \\
\text { practice of any profession in the Philippines }\end{array}$ \\
\hline & RA 7164: Philippine Nursing Act of 1991 \\
\hline & RA 8344: Hospital Doctors to treat emergency cases referred for treatment \\
\hline & $\begin{array}{l}\text { AO 114: Revised/updated the roles and functions of the Municipal Health Officers, Public Health Nurses and Rural Midwives } \\
\text { PMA. Medical Society by-laws }\end{array}$ \\
\hline Diffusion of eHealth & Free and Open Source Software (FOSS) \\
\hline \multirow{3}{*}{$\begin{array}{l}\text { Addressing the Digital } \\
\text { Divide }\end{array}$} & Community e-Centers (CeCs) \\
\hline & Deped: Gearing up Internet Literacy and Access for Students (GILAS) \\
\hline & DOH: Universal Health Care (UHC) \\
\hline \multirow{3}{*}{$\begin{array}{l}\text { Integration into Existing } \\
\text { Systems }\end{array}$} & DOH EA, ISSP \\
\hline & Philippine Government Interoperability Framework (PGIF) Advocacy \\
\hline & ICT4H: Standards and Interoperability \\
\hline \multirow{3}{*}{$\begin{array}{l}\text { Handling Innovation at } \\
\text { Different Levels }\end{array}$} & RA 8792: E-commerce Act \\
\hline & DOH: UHC \\
\hline & EO 269: Creating the Commission on Information and Communications Technology \\
\hline \multirow[t]{3}{*}{ Policy Goal Setting } & DOH: UHC, EA, ISSP, National eHealth Strategic Framework \\
\hline & ICT4H: Standards and Interoperability \\
\hline & RA 8792: E-commerce Act \\
\hline Evaluation and Research & Philippine Health Research Act of 2008 (University of the Philippines National Institutes of Health, National Telehealth Center) \\
\hline \multirow[t]{2}{*}{ Investment } & RA 8792: E-Commerce Act \\
\hline & $\begin{array}{l}\text { Philippine Health Insurance Corporation (PHIC) - policies on financing health workers working in remote areas, Primary Care } \\
\text { Benefit packages }\end{array}$ \\
\hline \multirow[t]{2}{*}{ Ethical Issues } & Philippine Medical Association (PMA) Code of ethics \\
\hline & RA 6713 - Code of Conduct and Ethical Standards for Public Officials and Employees \\
\hline
\end{tabular}


Table 2. Elements of eHealth policies in the Philippines using policy domain on networked care

\begin{tabular}{|c|c|c|}
\hline Policy Categories & Issues & Do policies exist to address issues? \\
\hline \multirow[t]{6}{*}{ Creating enabling environment } & Commitment of funds by the organization and governments & No \\
\hline & Readiness and effective change management & No \\
\hline & Deployment of appropriate technologies & No \\
\hline & Proper distribution of human resources & No \\
\hline & Reimbursements/remuneration & No \\
\hline & Meeting the needs of Insurance Companies & No \\
\hline \multirow{3}{*}{$\begin{array}{l}\text { Sharing of Information, knowledge } \\
\text { and practice }\end{array}$} & Sharing of patient information & No \\
\hline & Sharing of knowledge & No \\
\hline & Sharing of services, e.g., consultations, pharmacy etc. & No \\
\hline \multirow[t]{3}{*}{ Making transfer of information easier } & Functional interoperability & Yes \\
\hline & Semantic interoperability & Yes \\
\hline & Standardization measures for EHRs & Yes \\
\hline \multirow[t]{4}{*}{ Making transfer of information safer } & Security of information during portability & Yes \\
\hline & Ensuring integrity and quality of data/information & Yes \\
\hline & Health information privacy & Yes \\
\hline & Policies on managing health information on the Internet & Yes \\
\hline \multirow[t]{7}{*}{ Challenges for networked care } & Accountability/liability of care & No \\
\hline & Confidentiality/privacy & Yes \\
\hline & Ensuring proper connectivity & Yes \\
\hline & Controlling malpractice & No \\
\hline & Intellectual property rights & Yes \\
\hline & Risk management & No \\
\hline & Cultural issues in communication & No \\
\hline
\end{tabular}

Table 3. Elements of eHealth policies in the Philippines using policy domain on interjurisdictional practise

\begin{tabular}{|c|c|c|}
\hline Policy Categories & Issues & Do policies exist to address issues? \\
\hline \multirow[t]{2}{*}{ Professional portability } & Licensing & No \\
\hline & Accreditation of Service & No \\
\hline \multirow[t]{2}{*}{ Challenges in interjurisdictional practice } & Local, national, and international policies & Yes \\
\hline & Different health care regulations in different regions & No \\
\hline
\end{tabular}

Table 4. Elements of eHealth policies in the Philippines using policy domain on connectivity

\begin{tabular}{|c|c|c|}
\hline Policy Categories & Issues & Do policies exist to address issues? \\
\hline \multirow[t]{4}{*}{ Increasing penetration of services } & Telecommunications policies allowing increased access & Yes \\
\hline & Controlling cost of technology & No \\
\hline & Providing universal and unlimited access to Internet & Yes \\
\hline & Capacity building & No \\
\hline \multirow[t]{3}{*}{ Developing “Open” policies } & Open and facilitated exchange and sharing of skills and knowledge & No \\
\hline & Increasing focus on open-source policies & Yes \\
\hline & Humanitarian versus commercial policies & No \\
\hline
\end{tabular}

The fourth policy domain is integration into existing system. Only four out of 13 policies issues are addressed under the theme of integration into existing systems (Table 5). Health services are devolved to local government units, national policies and vertical public health programs are retained in the $\mathrm{DOH}$, and provision of health services is dominated by the private health sector. Local autonomy means that local government units (LGUs) can create or procure their own systems of delivering health services and information systems.

The fifth policy domain is handling innovation. This theme deals with the possibly disruptive aspect of eHealth. By its nature, new technology can be disruptive and adapting to it requires an environment that is able to transition smoothly and nimbly from one community or sector to another, a system that manages change, and people that are equipped to handle these. None of the nine elements are present in Philippine eHealth policy (Table 6).
The sixth policy domain is goal setting for eHealth policy. Six out of 14 policies issues are addressed by different policies in the status quo (Table 7). Goal-setting for eHealth guides institutions in defining policies. It sets the tone for governance, guidance of stakeholders, making policies flexible, and making eHealth feasible. Policy goal-setting for health is the function of the DOH. Since President Benigno S. Aquino, III, efforts of the DOH are concentrated on achieving universal health care as part of the overall development plan for the Philippines. The Aquino Health Agenda aims to achieve "better health outcomes, sustained health financing and responsive health system by ensuring that all Filipinos, especially the disadvantaged group in the spirit of solidarity, have equitable access to affordable health care" ${ }^{17}$

The seventh policy domain is evaluation and research. eHealth implementation like other programs needs to be evaluated. Its impact must be measured to guide policy and management. This theme involves two 
The Philippine Policy Context for eHealth

categories: (1) evaluating the impact of eHealth and (2) assessing new technologies. Majority of eHealth impact evaluation is limited to project evaluation. Assessment of new technologies is likewise limited. In the National Unified Health Research Agenda 2011, research on ICT for health still focuses on development of ICT solutions specifically on public health surveillance systems, telehealth services, interface for ICT-enabled medical devices and ICT-enabled health services. ${ }^{18}$ None of the 9 policy issues was present in the Philippin eHealth policy (Table 8).

Table 5. Elements of eHealth policies in the Philippines using policy domain on integration into existing systems

\begin{tabular}{lll}
\hline Policy Categories & Issues & Do policies exist to address issues? \\
\hline Achieving broader goals & Improving clinical effectiveness & No \\
through integration & Improving quality of care & No \\
& Increasing access to services & No \\
Facilitating integration & Reducing cost of care & No \\
& Defining scope of eHealth services & No \\
Identifying and involving stakeholders & Proper deployment of resources & Yhange in business rules in organizations and insurance companies \\
& Who are the stakeholders at different levels & Yes \\
Challenges with integration & What are the roles of different players & Yes \\
& Increasing acceptability among patients and providers & No \\
& Cider ethical acceptability & No \\
\hline
\end{tabular}

Table 6. Elements of eHealth policies in the Philippines using policy domain on handling innovation

\begin{tabular}{lll}
\hline Policy Categories & Issues & Do policies exist to address issues? \\
\hline Assigning definite roles & Who is responsible for change & No \\
& Who handles the problems & No \\
Managing change brought by & Regulating IT use & No \\
new technologies and ideas & Bridging changes in infrastructure & No \\
& Handling increasing communication cost & No \\
Assessing technologies & Change management & No \\
& Maintaining doctor-patient relationship & No \\
\hline
\end{tabular}

Table 7. Elements of eHealth policies in the Philippines using policy domain on policy goal-setting

\begin{tabular}{|c|c|c|}
\hline Policy Categories & Issues & Do policies exist to address issues? \\
\hline \multirow[t]{3}{*}{ Making eHealth possible/feasible } & Making eHealth part of the overall development effort & No \\
\hline & Funding of eHealth programs & Yes \\
\hline & $\begin{array}{l}\text { Providing suitable telecommunication infrastructure to promote } \\
\text { eHealth }\end{array}$ & Yes \\
\hline \multirow[t]{5}{*}{ Making policies flexible } & Aligning policies with IT innovations & Yes \\
\hline & Innovative and forward-looking policies & No \\
\hline & Covering for the opportunity cost of physicians, especially during the & \\
\hline & initial phase when volumes are low & No \\
\hline & Timing of government action & No \\
\hline \multirow[t]{3}{*}{ Providing effective governance } & Developing leadership structures for eHealth programs & No \\
\hline & Developing strategies for eHealth adoption & Yes \\
\hline & Information governance & Yes \\
\hline \multirow[t]{4}{*}{ Guidelines for different stakeholders } & Guidelines for organizational leadership & Yes \\
\hline & Guidelines for technology and equipment & No \\
\hline & Guidelines for clinical standards and outcomes & No \\
\hline & Guidelines for human resources & No \\
\hline
\end{tabular}

Table 8. Elements of eHealth policies in the Philippines using policy domain on evaluation and research

\begin{tabular}{lll}
\hline Policy Categories & Issues & Do policies exist to address issues? \\
\hline Evaluating the impact brought by eHealth & Time spent with patients and its relationship with cost & No \\
& Cost-effectiveness & No \\
& Impact of eHealth on health care management & No \\
& Demonstrate health outcomes & No \\
& Evidence on clinical effectiveness & No \\
Assessing technologies & Progress in learning & No \\
& Providing simulation environment & No \\
\hline
\end{tabular}


Table 9. Elements of eHealth policies in the Philippines using policy domain on investment

\begin{tabular}{lll}
\hline Policy Domain/Category & Issues & Do policies exist to address issues? \\
\hline Investment & Use of eHealth for commercialization purposes & Yes \\
& Public-private partnership & Yes \\
& Cross-border advertisement and sale of drugs & No \\
\hline
\end{tabular}

Table 10. Elements of eHealth policies in the Philippines using policy domain on ethical issues

\begin{tabular}{lll}
\hline Policy Domain/Category & Issues & Do policies exist to address issues? \\
\hline Ethical issues & Consent for care in eHealth & Yes \\
& Liability issues (medical malpractice liability) & No \\
& Medico-legal issues & No \\
& Patient's right to access information & No \\
\hline
\end{tabular}

The eighth policy domain is investment. This theme covers the following issues: (1) use of eHealth for commercialization purposes, (2) public-private partnership, and (3) cross-border advertisement and sale of drugs. The policies in the status quo do not adequately address these issues. Many private investors have funded and are running eHealth implementation in many private and some public hospitals all over the country. PhilHealth as the prime mover in health financing especially for the poor is investing in health information management and incentivizes the use of electronic health information systems in the public health sector. The $\mathrm{DOH}$ has invested in many projects to deliver health services using ICT but not a scale of a regular program. Two out of the three policy issues are present in the Philippine eHealth policy (Table 9).

The ninth policy domain is ethics in eHealth. The issues included in this theme are (1) consent for care in eHealth, (2) liability issues (medical malpractice liability), (3) medico-legal issues, and (3) patient's right to access information. Obtaining consent for procedures such as surgeries is standard practice in the Philippines. However, there is a limitation on the transferring information into electronic media and getting images for videoconferencing or telemedicine. The Data Privacy Act of 2011 mandates that consent be obtained before storing any information about a person and obligates the one getting the information to explain the purpose, mechanism for transmission, and third persons who may access the data. Only one of the three policy issues has been addressed in the Philippine eHealth policy (Table 10).

\section{Discussion}

Based on the data presented above, a discourse on the various domains is elaborated. There are known organizational obstacles to the successful implementation of eHealth. One of which is the issue of interoperability which means that long-term integration of technologies have not been effected but instead, a piecemeal development of the telecommunications infrastructure has resulted in "health care which promotes the adoption of health information technologies that cannot "speak" to one another. ${ }^{19}$ Craft defines interoperability as "the ability of a system or product to work with other systems or products without special effort on the part of the customer" ${ }^{20}$ In other words, there is no connectivity with other systems because they do not share the same software and hardware, or these tools are incompatible to each other in various locations and geographies. In the end, the objective of mainstreaming eHealth is undermined because of the problem of interoperability. In becomes even more problematic in a setting like that in the Philippines, where health is devolved to the local government units. In such situations, the decentralized health care systems are not compatible with the centralized system, or in some cases, the local unit is hesitant to adopt the eHealth model of the central unit.

Networked care deals with the interconnected nature of healthcare systems. This highlights the importance of enabling the smooth flow of information to ease the transfer of patient information and care from one provider to another. In the Philippines, the integration of healthcare providers into one network is not well-defined especially in the context of devolution where provisions of health services are lodged at different levels of often uncoordinated providers.

The issue of interoperability can be addressed by an administrative order ( $\mathrm{AO}$ ) recently drafted by the $\mathrm{DOH}$, a result of several consultative forums initiated and participated in by various sectors. In 2010, DOH Secretary Ona organized the ICT4Health Technical Working Group to assist the Department in developing eHealth as an enabling tool towards universal health care. Consisting of representatives from relevant government agencies, private sector and academe (the University of the Philippines National Telehealth Center), recommendations emanating from broader consultations were presented in February 2012 in areas of enterprise architecture, standards to ensure interoperability and compliance with these standards, and capacity building. The result of these consultative forums became the basis of the DOH AO. The Department of Budget Management in 2012 launched the government-wide Medium Term Information and Communications Technology Harmonization Initiative (MITHI) in order to harmonize all resources, programs and projects in the entire government, and resolve problems of restricted databases, turf wars, and lack of interoperability. However, the transfer 
of information among and across different health facilities easier remains to be a challenge given the current health system in the country. Additionally, there may be potential flash points between easing transfer of data from one facility to another due to the Data Privacy Act.

The practice of medical professions in a networked care model poses challenges in accountability/liability of care, controlling malpractice, addressing cultural issues in communication and risk management. In the Philippines, both medical liability and malpractice have been defined by laws formulated in the 1950s and do not cover the practice of telemedicine which is a recent development. The liability of physicians or nurses practicing telemedicine to what happens to a patient under their care still has to be categorically defined. This has presented a dilemma for both practitioners and patients. On one hand, practitioners are cautious or even hesitant to offer healthcare services due to the ambiguity of liability clause. On the other hand, the patients may not feel protected adequately by this liability clause. This ambiguity can also expose the medical practice to malpractices from unscrupulous practitioners who may cash in on the ease of its use.

Likewise, there is also the problem of interjurisdictional practice. While there are laws that permit the practice of foreign healthcare professionals in special circumstances and for a limited period each time, there are no laws that define or regulate routine telemedicine practice, exchange of health information, and licensing of telemedicine practice across national borders.

In terms of the diffusion of eHealth, the government has attempted to reduce this digital divide by enacting certain laws to prevent monopoly enterprises and introduce competition in the market. There are also projects sponsored by government in the community such as eCenters, and the adoption of new wireless data communications standard called TV White Space (TVWS) technologies.

On the need for integration into existing systems, there are inherent problems in the Philippine context. Health services are devolved to local government units, national policies and vertical public health programs are retained in the $\mathrm{DOH}$, and provision of health services is dominated by the private health sector. Local autonomy means that LGUs can create or procure their own systems of delivering health services and information systems. It is in this area where problems of interoperability may arise because the different players have a wide latitude in implementing information management systems, e.g. freedom to choose type of IT system and which provider to get. The role of the $\mathrm{DOH}$ is to set the information standards and facilitate health information exchange in order to integrate health information coming from independent players in the health sector. This is effected in order to form a unified set of Philippine health information. In this regard, the $\mathrm{DOH}$ Information Management Service (IMS) has drafted in 2012 an administrative order entitled National Implementation of Health Data Standards for Interoperability. It is vital that the national bureaucracy mandated for health matters, which in the Philippines is the DOH, set standards for health information technology providers and a certification process to protect the consumers, i.e. healthcare providers from unscrupulous providers.

In the Philippines, eHealth implementation is at its early stages, however, definite guidelines on how to handle innovation have yet to be set. Managing practical aspects of innovation across the different levels of government especially in rural and remote areas where innovations are few and far between has presented as a shortcoming.

In terms of eHealth policy goal-setting, the National Objectives for Health 2011 to 2016 sets the goals and strategies by the DOH. The goal for eHealth is "to establish harmonized, quality, relevant and responsive eHealth services to provide the necessary tools, data, information and knowledge for evidence-based policy and program development towards the provision of accessible, quality, affordable, efficient and safe health services and attainment of better health outcomes for all Filipinos". ${ }^{21}$

The strategies include: 1.) Development and promotion of the eHealth agenda; 2.) Development, promotion and adoption of critical health application systems, including real time reporting and recording of health information; 3.) Adoption of national data, ICT and relevant eHealth standards; 4.) Enhancement and expansion of stakeholder collaboration for both health data producers and users under the Philippine Health Information System and ICT for Health; 5.) Creation of the National Telehealth Services Program; and 6.) Public-private partnership for eHealth and development and implementation of various systems.

The strategic objectives above reflect the priorities of a country in the earlier stage of eHealth implementation: they are largely oriented towards setting agenda and providing eHealth services. The Philippine eHealth agenda is elaborated in the Philippine eHealth Strategic Framework, the current version in draft form covers the period of 2013 to 2017.22 It describes in detail the eHealth components: (1) Enabling Structures and Resources, (2) Mission Critical Health Application Systems, (3) Philippine Health Information System, (4) Knowledge Management for Health, and (5) Telemedicine/mHealth Capacities.

The Department of Science and Technology (DOST) is another stakeholder in eHealth. DOST pioneered an eHealth program in 2007 called the Institutionalization of the National Telehealth Service Program. Recently, a joint circular of the $\mathrm{DOH}$ and the DOST was forged towards eHealth development in the country, and public discussion on the proposed Philippine eHealth Strategic Framework 2013-2017 was among its first output.

Implementation of eHealth solutions should not also merely focus on pilot tests, but to also cover the actual 
implementation of eHealth programs that have been implemented for years. So far, there are no policies that deal with eHealth impact evaluation such as the purported benefits of reduced patient waiting time, increased data quality, cost-effectiveness, and demonstrated improvement in health outcomes. There are no assessment studies on standards to ensure that eHealth implementation is optimized. The adoption of technology research is done by academic institutions but on a limited scale and its application to policy has yet to be demonstrated.

As a policy statement, the $\mathrm{DOH}$ encourages publicprivate partnerships in eHealth. ${ }^{22}$ The new PhilHealth law mandates that eHealth applications will be used as tools to deliver health care services, especially in geographicallyisolated and disadvantaged areas, and be funded. ${ }^{23}$ However, unless a program has regular fund allocation, eHealth will remain at a small scale.

In terms of liability and medico-legal issues, liability clauses have yet to be defined. So far, the law does not even offer a definition of telemedicine. There is one area of clarity - the law on patient's rights to access information and has sovereignty over it.

Globally, various ethical concerns in eHealth have been defined and used by implementers of eHealth projects like the University of the Philippines Manila, as guide in the ethical practice of eHealth. Professional codes of conduct as well as the public servants code of ethics also serve as basis for the direction and guidance for practitioners of eHealth.

Indeed, there are many domains for policy consideration and eventual prioritization. The themes are similar to policy evaluation areas used by other researchers abroad. For instance, Jennett and Andruchuk provide practical observations in the case of Canada's adoption of telehealth for its successful implementation. ${ }^{6}$ First, the environment must be ready to accommodate telehealth such as workstation and information technology (IT) standards for fostering interoperability and interconnectivity across regional, provincial, territorial and national networks, along with adequate human capacity to manage, operate and monitor the telehealth infrastructure. Second, there is a growing realization that telehealth is a partial solution to the need for health restructuring and reform to address issues of lack of access, maldistribution of health resources, rising cost of healthcare, medical inefficiencies and malpractices and lack of evidence-based timely decisions. Furthermore, there is an emphasis that Health should also be understood as having a unique cultural component because traditions and religious beliefs shape the consumer's health practices and beliefs.

In the study of Cramer and Englund, the political feasibility of passing telehealth legislation is hindered by issues including: perceived technology complexity, concern over practitioner competence, start-up costs, the potential for unethical billing practices, the need for professional certification requirements, problems associated with the lack of compatible information systems standards, and the potential for regulatory fraud and misconduct. ${ }^{7}$ There is also the concern over increased start-up costs and the increasing cost to maintain the equipment telehealth.

Policy analysis has a rapid turnaround because of the need and practicability of coming up with legislations based on policy analysis. Policymakers and decision makers need to have a framework on how to best evaluate existing or proposed policies that will benefit the greater majority of their constituents and stakeholders. This framework should also be backed up by evidence from existing studies conducted in the field of telehealth. This framework identifying policy domains was carried out in this research study, in an attempt, to identify qualitatively aspects of policy analysis that can be consequently pursued.

The study merely covered internet sources which can be considered as a rigorous tool in analyzing data. This presents as a limitation of the study. It is recommended that interviews and data collection be gathered from concerned agencies to validate or complement the results of this study. The latter research methodology, however, may also present another caveat when data are not readily shared by the concerned agencies, or when their data collection and storage are not complete. Another limitation of the study is that it might have missed data on policies and programs on eHealth in the Philippines, especially those that are not made readily available online.

\section{Conclusion}

The study has covered existing internet literature on existing regulations, policies and programs on eHealth in the Philippines for analysis of certain policy domains that may serve as a tool in the successful implementation of eHealth. These policy domains were adopted form the study of Khoja et al. Currently, eHealth implementation in the country is still at the beginning stages and in order for it to mature and be successful, it is recommended that gaps in policies described here be addressed. The current policies are a step towards the right direction. Revisions of existing laws and enactment of new ones such as on the licensing of telemedicine as a practice, regulations of private practice are needed to help foster eHealth.

\section{References}

1. Scott RE, Chowdhury MF, Varghese S. Telehealth policy: looking for global complementarity. J Telemed Telecare. 2002; 8 Suppl 3:S3:55-7.

2. Wachter RM. The "dis-location" of U.S. medicine - the implications of medical outsourcing. N Engl J Med. 2006; 354(7):661-5.

3. Schwamm LH, Rosenthal ES, Hirshberg A, et al. Virtual TeleStroke support for the emergency department evaluation of acute stroke. Acad Emerg Med. 2004; 11(11):1193-7.

4. Blumenthal D. Stimulating the adoption of health information technology. N Engl J Med. 2009; 360(15):1477-9. 
5. The Library of Congress. US American Recovery and Reinvestment Act of 2009 (ARRA) [Online]. 2009 [cited 2016 Feb]. Available from http://thomas.loc.gov/cgi-bin/query/z?c111:H.R.1.enr:.

6. Jennett PA, Andruchuk K. Telehealth: 'real life' implementation issues. Comput Methods Programs Biomed. 2001; 64(3):169-74.

7. Prinz L, Cramer M, Englund A. Telehealth: a policy analysis for quality, impact on patient outcomes, and political feasibility. Nurs Outlook. 2008; 56(4):152-8.

8. Kluge EH. Ethical and legal challenges for health telematics in a global world: telehealth and the technological imperative. Int J Med Inform. 2011; 80(2):e1-5.

9. Khoja S, Durrani H, Nayani P, Fahim, A. Scope of policy issues in eHealth: results from a structured literature review. J Med Internet Res. 2012; 14(1):e34.

10. The Rockfeller Foundation. Making the eHealth Connection [Online]. Archbishop Desmond Tutu Launches Bellagio eHealth Call to Action during Global Ministerial Forum for Research on Health in Bamako, Mali [Video]. 2008 Nov 18 [cited 2013 Jun]. Available from http://www.ehealth-connection.org/content/archbishop-desmond-tutulaunches-bellagio-ehealth-call-action.

11. Scott R. Sparking eHealth innovations. Technology Enabled Knowledge Translation Investigative Centre (TEKTIC) [Online]. 2008 [cited 2016 Mar]. Available from http://www.tektic.ca/tektic_team/richard-scott/.

12. Lewis T, Synowiec C, Lagomarsino G, Schweitzer J. E-health in low- and middle-income countries: findings from the Center for Health Market Innovations. Bull World Health Organ. 2012; 90(5):332-40.

13. The Rockefeller Foundation. Making the eHealth Connection: Bellagio eHealth Call to Action [Online]. 2008 [cited 2013 Jun]. Available from http://ehealth-connection.org/content/bellagio-ehealth-call-action.

14. Kallander K, Tibenderana JK, Akpogheneta OJ, et al. Mobile health (mHealth) approaches and lessons for increased performance and retention of community health workers in low- and middle-income countries: a review. J Med Internet Res. 2013; 15(1):e17.
15. Agcaoili L. Internet Penetration rises to 35\%. Philippine Star [Online]. 2013 Feb 2 [cited 2013 Jun]. Available from http://www.philstar.com/ business/2013/02/02/903770/internet-penetration-rises-35.

16. Freedom House: Freedom on the Net 2012 [Online]. Washington DC:Freedom House; 2012 Sept [cited 2013 Jun]. Available from. http:// www.freedomhouse.org/sites/default/files/Philippines\%202012.pdf.

17. Administrative Order No. 2010-0036. The Aquino Health Agenda: Achieving Universal Health Care for All Filipinos. Department of Health. Manila, 2010.

18. National Unified Health Research Agenda 2011-2016. Philippine Center for Health Research and Development. Department of Science and Technology. Manila, 2011.

19. Miller E. Telemedicine and the Provider-Patient Relationship: What We Know So Far. Report prepared for the Nuffield Council's Working Party on The Ethics of 'Personalized' Medicine in a Consumer Age [Online]. 2010 Jan 17 [cited 2016 Feb]. Available from http://nuffieldbioethics. org/wp-content/uploads/Miller-E-2010-Evidence-review-Telemedicineand-the-Provider-Patient-Relationship-what-we-know-so-far.pdf.

20. Craft RL. Toward technical interoperability in telemedicine. Telemed J E Heatlh. 2005; 11(3):384-404.

21. 2011-2016 National Objectives for Health, Health Sector Reform Agenda Monographs. (DOH HSRA Monograph No. 12). Department of Health. Manila, Republic of the Philippines, 2011.

22. Department of Health. Information Management Service: Philippines eHealth Strategic Framework and Plan 2013-2017 Draft [Online]. 2013 January 23 [cited 2013 Jun]. Available from http://uhmis1.doh.gov.ph/ UnifiedHMIS/images/pdf/ Philippines_eHealthStrategicFrameworkPlan_Version1_Jan23_2013.pdf.

23. Republic Act No. 10606: An Act Amending Republic Act No. 7875, Otherwise Known as the "National Health Insurance Act of 1995", as Amended, and for Other Purposes. July 23, 2012. 